Ann. Biol. anim. Bioch. Biophys., 1977, 17 (2), 165-172.

\title{
Bull spermatozoa in the female tract after natural mating A preliminary ultrastructural study of uterotubal junction
}

\author{
par Marie-Louise KANN*, J. P. FOUQUET \\ Laboratoire de Biologie Cellulaire, Université Pierre-et-Marie-Curie \\ 7, quai Saint-Bernard, 75230 Paris Cedex 05, France
}

Summary. Bull spermatozoa found in the cow genital tract 18 hours postcoitum are observed in situ by both light and electronic microscopy after the uterotubal junction and its surrounding area are fixed. No phagocylosis is evident then, and many spermatozoa are seen in the folds of the uterotubal junction mucosa. None of the spermatozod evidence ultrastructural integrity. Some show only periacrosomal plasma membrane rupture, while others are damaged more seriously, causing changes in the acrosome as well.

The cow uterotubal junction does not thus seem a favorable site for spermatozoon survival ; it rather acts as a filter, reducing the number of spermatozoa reaching the fertilization site.

\section{Introduction.}

During natural mating in mammals spermatozoa must travel a long way in the female genital tract before reaching the egg. The duration of transit, its selective effect and consequences on the survival and viability of spermatozoa are not fully understood (Thibault and Levasseur, 1973 ; Bedford, 1974 ; Austin, 1975a).

However, during this transit the spermatozoa are capacitated and thus prepared for fertilization. The first evidence of this process is a coordinated true acrosome reaction in the close proximity of the oocyte investments (Bedford, 1970, 1974 ; Austin, $1975 b$ ). This theory, studied in vitro and in rodents (Yanagimachi and Noda, 1970 ; Zamboni, 1971 ; Bedford, 1970, 1972), seems to be confirmed in pig (Szöllösi and Hunter, 1973) and man (Soupart et al., 1974). It is necessary to know the fate of spermatozoa in situ in order to obtain a better understanding of the role played by the

* Present adress : Laboratoire de Physiologie de la Reproduction des Vertébrés. Université, Pierre-et-Marie-Curie, 7, quai Saint-Bernard, 75230 Paris Cedex 05, France. 
female tract in transit and the various physiological aspects of spermatozoa. In the present investigation, we have done an ultrastructural study of spermatozoa ascending the cow genital tract.

\section{Material and methods.}

Two cows of proven fertility were mated once during estrus with a known breeder bull and slaughtered $18 \mathrm{~h}$ later. The genital tract was quickly removed; both uterine horns and the fallopian tube of the cows were dissected and fixed within $10 \mathrm{mn}$ in a 3 p. 100 glutaraldehyde solution buffered with cacodylate $0.1 \mathrm{M}$ at $\mathrm{pH} 7.3$. Fixation was continued for 4 hours at $4^{\circ} \mathrm{C}$ by both immersion and slow perfusion into the lumen from the oviduct to the uterus. The uterotubal junction and the proximal part of the isthmus were cut into small pieces, selected only because at $18 \mathrm{~h}$ postcoitum they present the highest number of spermatozoa (Thibault ef al., 1973).

These fragments were washed, postfixed $2 \mathrm{~h}$ in $2 \mathrm{p} .100 \mathrm{OsO}_{4}$ in the same cacodylate buffer plus $0.25 \mathrm{M}$ sucrose, then dehydrated and embedded in Epon. Thick and thin serial sections were cut with a glass knife in a Reichert automatic microtome. Thick sections were observed directly with a phase-contrast microscope ; thin sections were stained with uranyl acetate and examined with an HU 11B Hitachi electron microscope.

\section{Results.}

\section{Spermatozoon distribution.}

Though ovulation was unilateral, spermatozoa were present in both uterotubal junctions and the surrounding areas. Distribution was recorded only on the ovulatory side where they seemed more numerous. It clearly appeared that spermatozoon density was maximum in the folds of the uterotubal junction wall (pl. 1, fig.1) ; no spermatozoa were found in the lumen. In the preceding segments of the uterine horn the

\section{PLATE I}

FIG. 1. - Phase contrast micrograph of a group of bull spermatozoa (Sp) between two folds of the uterofubal junction. $\times 1500$.

FIGS 2, 3. - Control spermatozoa in fresh semen before insemination. About 62 p. 100 are unaltered spermatozod with plasma membrane (PM) adhering to the acrosome (A) (fig. $2, \times 36000$ ); about 30 p. 100 of spermatozoa have a swollen plasma membrane surrounding the acrosome and possibly the post-nuclear cap (PC) (fig. $3, \times 45000)$.

FIG. 4. - Fertilizing spermatozoon in the zono pellucida (ZP) of an egg recovered $23 \mathrm{hrs}$ after insemination This spermatozoon has undergone acrosome reaction but there are no abnormal signs of alteration. The posterior limit of the disappearing acrosome is indicated by an arrow ( $\times 22000)$. 

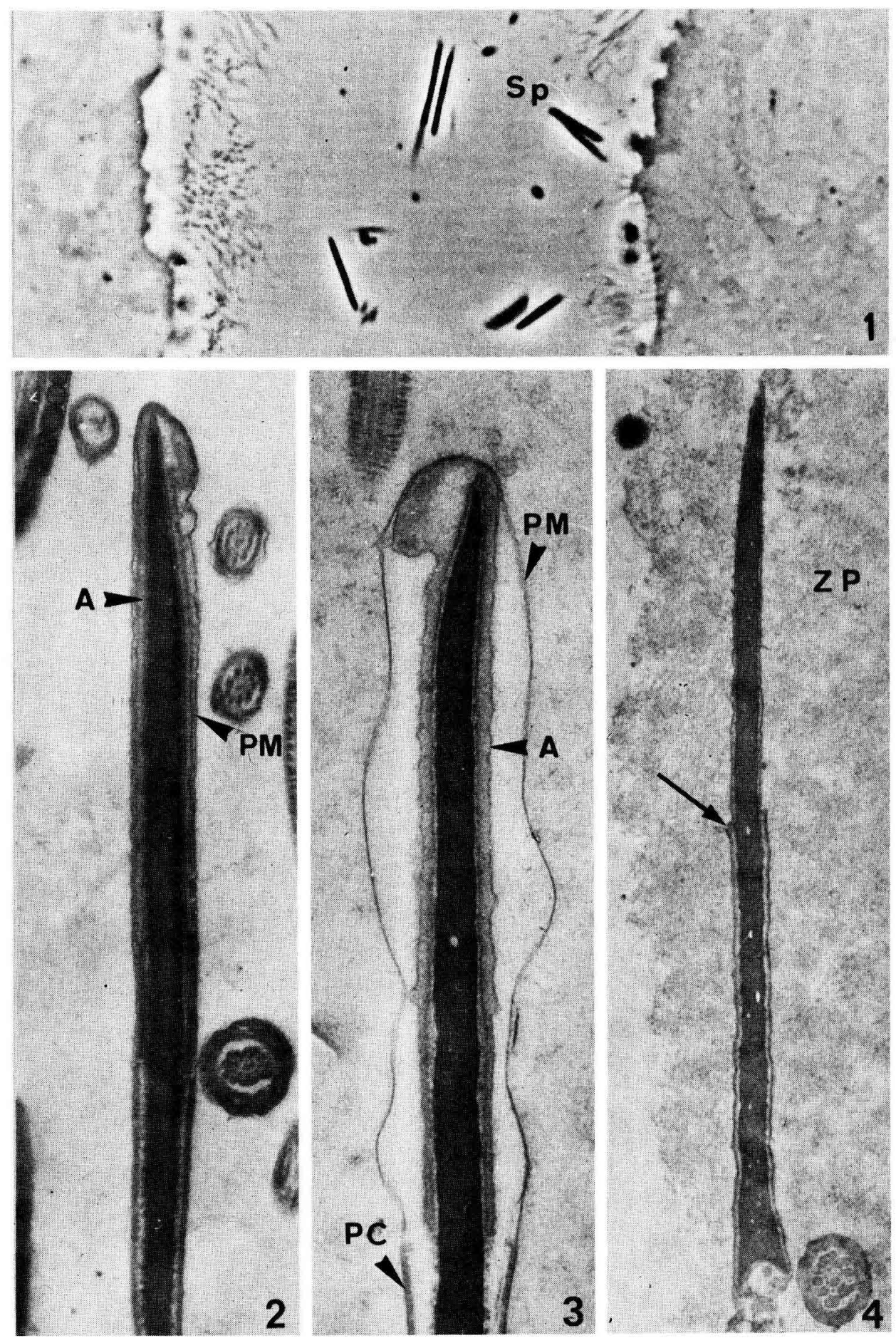
lumen was also devoid of spermatozoa. They were much less numerous and more or less deeply located in the uterine glands, and were barely observed in the first segments of the isthmus near the base of mucosa villous projections.

In the uterine horn as well as at the base of the isthmus, spermatozoa were usually isolated. Sometimes they formed small groups (10-20 cells) in the uterotubal junction, showing no particular orientation. Phagocytosis figures were not noted in the lumen or in the epithelium at any level.

\section{Spermatozoon ultrastructure.}

We studied approximately 500 spermatozoa showing more or less pronounced signs of alteration. Only the head was modified, whereas the tail was intact from middle piece to terminal piece (pl. 2, fig. 4). From the nature of the damage we arbitrarily defined two morphological types of spermatozoa; their distribution was independent of the area in which they were found.

In the first type, the spermatozoon plasma membrane was swollen and broken (pl. 2, fig. 1) but the acrosome was perfect in form and electronic density. This represented more than one-half of the population examined. Plasma membrane damage occurred over the entire head region, the anterior acrosomal surface being more often injured than the post nuclear cap region.

In the second type, the spermatozoon plasma membrane was not only ruplured but the acrosome was also swollen. The outer acrosomal membrane was usually ruptured, allowing the contents to escape (pl. 2, fig. 2, 3), but the inner acrosomal membrane continued to surround the perinuclear substance.

The nucleus remained intact in all the structural types studied. Moreover, free membrane remnants (possibly vesicles) persisted near the sperm head. These remnants could represent fragments of either plasma membrane or outer acrosomal membrane (pl. 2, fig. 1, 2, 3). However, fusion between the plasmalemma and the outer acrosomal membrane was not observed, and no other aspects suggesting true acrosome reaction were noted (Bedford, 1970).

PLATE ॥

FIGS 1-4. - Eleciron micrographs of spermatozoo through the uterotubal junction.

FIG. 1. - Note the rupture of the plasma membrane (PM), presence of vesicle remnants (arrows) and intact acrosome (A). $\times 48000$.

FIGS 2, 3. - Note the swelling of the acrosome cap (ac), intact equatorial segment (es) and probable plasmalemma remnants (arrow) (fig. $2, \times 26000)$. Higher magnification in fig. $3(\times 60000)$ shows the alteration of the outer acrosomal membrane (oac).

FIG. 4. - Unaltered sperm tail seen at the level of the Jensen ring (Jr). $\times 48000$. 

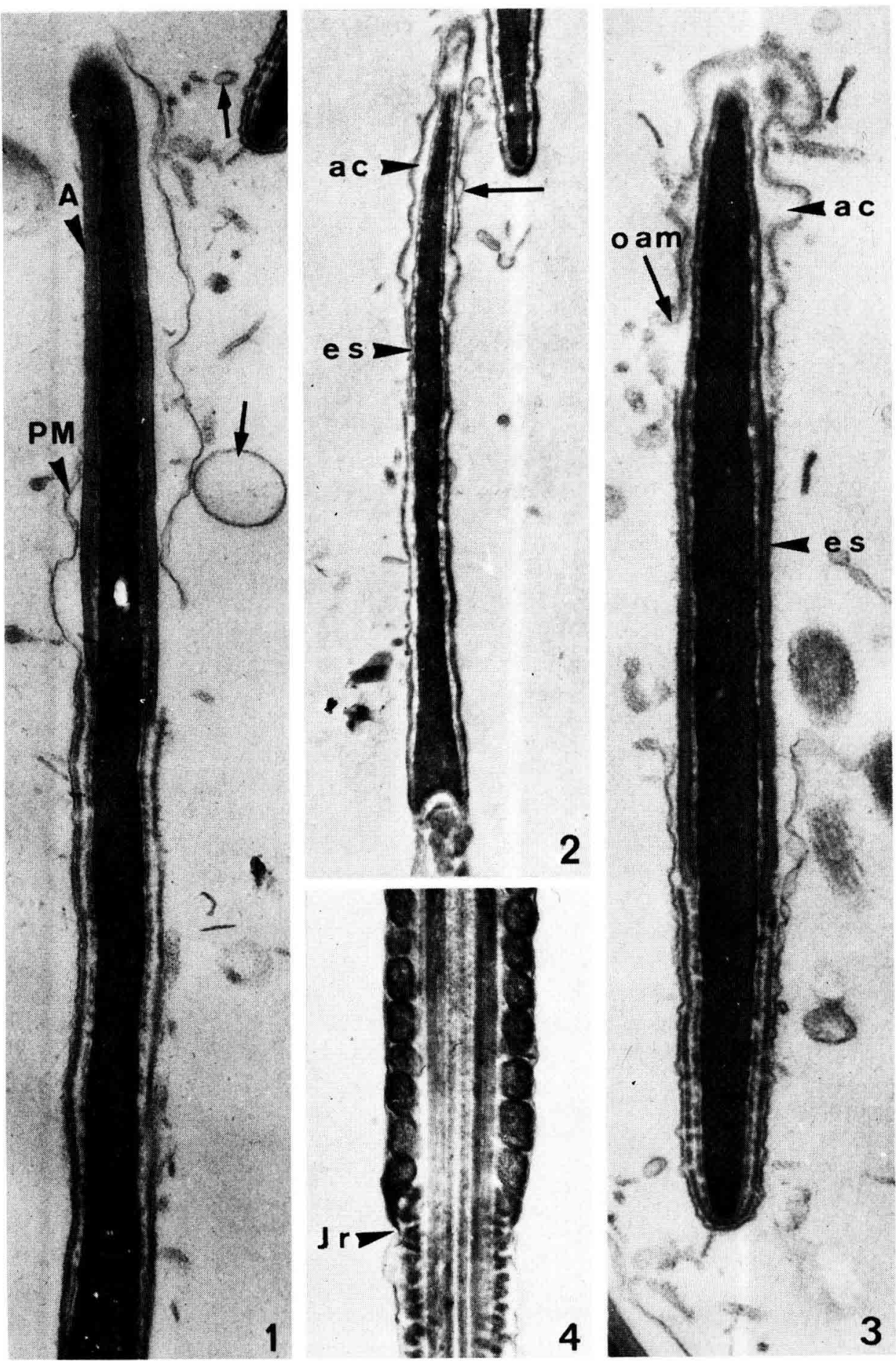


\section{Discussion.}

Using light microscope observation, Thibault ef al. (1973) showed that $18 \mathrm{~h}$ after mating an estrous cow, spermatozoa accumulate in the uterotubal junction, while there is a smaller concentration in its surrounding area. This number diminishes progressively in the next $48 \mathrm{~h}$.

We judged $18 \mathrm{~h}$ postcoitum as optimum for a preliminary ultrastructural study of spermatozod during ascent in the female genital tract. The distribution observed in the limited area of the uterotubal junction and its vicinity is in good agreement with that described by Thibault et al. (1973).

That the spermatozoa studied show signs of degeneration possibly related to the false acrosome reaction of Bedford (1970) could be due to inadequate fixation, as suggested by the work of Mergounis (1974). However, a large number of spermatozoa with intact membranes is always found in samples of fresh or frozen semen, fixed and embedded as indicated in Material and Methods (pl. 1, fig. 2, 3). Spermatozoa in the zona pellucida of eggs recovered by this fixation procedure are well preserved (pl. 1, fig. 4).

Since the spermatozoa observed at $18 \mathrm{~h}$ postcoitum do not retain their structural integrity when they are far from the fertilization site, it seems doubtful that the viability or motility of even those with an intact acrosome could be maintained. This point of view is confirmed by the recent observations of Overstreet and Cooper (1975) who showed that at least the plasma membrane is altered in most non-motile spermatozoa in the female rabbit genital tract.

However, in the cow the uterotubal junction has been considered to be the spermatozoon reservoir (Thibault and Levasseur, 1973 ; Thibault et al., 1973). This implies that spermatozoa accumulate at this place before ovulation ; escaping progressively into the isthmus, they are protected from the leukocytic invasion which occurs elsewhere. Our observations suggest that the uterolubal junction might play a filtering role, thus decreasing the number of spermatozoa reaching the ampulla. The absence of macrophages is not a warrent for spermatozoon security because tubal epithelial cells have phagocytic activity (Chakraborty and Nelson, 1975) and spermatozoa may cytolyze (Austin, 1975a). In this hypothesis, which remains to be confirmed, the storage sites (Austin, 1975a ; Thibault and Levasseur, 1973) (if they exist) must be investigated at other levels of the genital tract, as the cervix.

It is surprising to see no intact spermatozoa $18 \mathrm{~h}$ postcoitum since they remain motile and fertile longer in the female tract (Austin, 1975a). These spermatozoa are recovered by tubal flushing which probably carries away only those in the isthmus and uterine lumen without touching the others hidden in the uterotubal junction folds or in uterine glands. We never observed spermatozoa in the uterotubal junction lumen, although they have been seen in great number at this site (Thibault ef al., 1973). As they were probably discarded during perfusion of the fixative solution, in one experiment we perfused the isthmus and the uterine horn with PBS solution. After concentration by mild centrifugation, some spermatozoa were recovered and observed by phase-contrast microscopy. Some were dead, but others were motile and apparently intact. Unfortunately, there were too few for electron microscopic study. 
Capacitation does not promote any structural modification of spermatozoa (Bedford, 1970, 1974), except a thinness of the cell coat, particularly upon the head (Gordon ef al., 1975 ; Austin, 1975 b). True acrosome reaction occurs only in the vicinity of egg investments. Nevertheless, it is not always easy to distinguish between a true and a false acrosome reaction (Zamboni, 1971) ; these acrosome reactions can occur before the gametes meet (Bedford, 1970 ; Zamboni, 1971). On the other hand, the membrane integrity of capacitated rabbit spermatozoa appears uncertain on the basis of scanning observations recently presented by Motta and Blerkom (1975). True acrosome reaction has been induced in vitro in bull spermatozoa with no egg present (Wooding, 1975) ; preliminary in vivo studies of fertilization in cow (Kann et al., 1976) appear to reveal a true acrosome reaction, but the exact time at which if occurs remains uncertain.

Accepté en septembre 1976.

Résumé. Les spermatozoïdes de Taureau rencontrés dans le tractus génital de la Vache $18 \mathrm{~h}$ post coïtum ont été observés in sifu au microscope à contraste de phase et au microscope électronique après fixation de la jonction utérotubaire et des régions voisines. A ce moment il n'y a pas encore de phagocytose et de nombreux spermatozoïdes sont observés dans les replis de la muqueuse de la jonction utérotubaire, aucun d'eux n'ayant conservé son intégrité structurale. Certains ne montrent que des ruptures de la membrane plasmique au niveau de la tête, d'autres ont des lésions plus sévères avec altération de l'acrosome en plus de celle de la membrane plasmique. A la suite de ces observations, il apparaît que la jonction utérotubaire de la Vache ne doil pas être un site favorable à la survie des spermatozoïdes, mais plutôt un filtre destiné à réduire le nombre de spermatozoïdes susceptibles d'atteindre le site de fécondation.

\section{References}

AUSTIN C. R., 1975a. Sperm fertility, viability and persistence in the female tract. J. Reprod. Fert., Suppl. 22, 75-89.

AUSTIN C. R., 1975b. Membrane fusion events in fertilization. J. Reprod. Fert. 44, 155-166.

BEDFORD J. M., 1970. Sperm capacitation and fertilization in Mammals. Biol. Reprod., Suppl. 2, 128 158.

BEDFORD J. M., 1972. An electron microscopic study of sperm penetration into the rabbit egg after natural mating. Amer. J. Anat., 133, 213-254.

BEDFORD J. M., 1974. Maturation of the fertilizing ability of mammalian spermatozoa in the male and female reproductive tract. Biol. Reprod., 11, 346-362.

CHAKRABORTY J., NELSON L., 1975. Fate of surplus sperm in the fallopian tube of the white mouse. Biol. Reprod., 12, 455-463.

GORDON M., DANDEKAR P. V., BARTOSZEWICZ W., 1975. The surface coat of epididymal. ejaculated, and capacitated sperm. J. Ulir. Res., 50, 199-207.

KANN M. L., GODARD-SIOUR C., PAREZ M., 1976. Ultrastructural observations on sperm penetration into the cow egg investments after in vivo fertilization. VIllth Int. Cong. Anim. Reprod. Artif. Insem., Cracow (in press).

MERGOUNIS D. J., 1974. Modifications ultrastructurales, cytochimiques ef enzymatiques des spermatozoïdes de Verrat après congélation. Thèse $\mathrm{Dr} \operatorname{lng}^{\mathrm{r}}$, Paris. 
MOTTA P., BLERKOM J. V., 1975. A scanning electron microscopic study of rabbit spermatozoa in the female reproductive tract following coïtus. Cell. Tiss. Res., 163, 29-44.

OVERSTREET J. W., COOPER G. W., 1975. Reduced sperm motility in the isthmus of the rabbit oviduct. Nature, 258, 718-719.

SOUPART P., STRONG P. A., 1974. Ultrastructural observations on human oocytes fertilized in vitro. Fertil. Steril., 25, 11-44.

SZOLLOZI D., HUNTER R. E. F., 1973. Ultrastructural aspects of fertilization in the domestic pig : sperm penetration and pronucleus formation. J. Anat., 116, 181-206.

THIBAULT C., GÉRARD M., HEYMAN Y., 1973. Transport ef survie des spermatozoïdes chez la Vache. In HAFEZ E. S. E., THIBAULT C. G. Sperm transport, survival and fertilizing ability. I. N. S. E. R. M. Paris, 26, 343-356.

THIBAULT C., LEVASSEUR M. C., 1973. Conservation et survie prolongée des spermatozoïdes dans les voies génitales femelles des Vertébrés. Ann. Biol. anim. Bioch. Biophys., 13, 267-284.

WOODING F. B. P., 1975. Studies on the mechanism of the hyamine induced acrosome reaction in ejaculated bovine spermatozoa. J. Reprod. Fert., 44, 185-192.

YANAGIMACHI R., NODA Y. D., 1970. Ultrastructural changes in the hamster sperm head during fertilization. J. Ultr. Res., 31, 465-485.

ZAMBONI L., 1971. Fine morphology of mammalian ferfilization. Harper and Row, Pubs., New York. 